\title{
Experimentação contextualizada e interdisciplinar: uma proposta para o ensino de ciências
}

\section{Contextualized and interdisciplinary experimentation: a proposal for the teaching of sciences}

\author{
Anelise Grünfeld de Luca (anelise.luca@gmail.com) \\ Instituto Federal Catarinense- Campus Araquari, SC. \\ Sandra Aparecida dos Santos (esasandra@unidavi.edu.br) \\ Centro Universitário para o Desenvolvimento do Alto Vale do Itajaí, SC. \\ José Claudio Del Pino (delpinojc@ yahoo.com.br) \\ Universidade Federal Do Rio Grande do Sul, RS.
}

Michelle Camara Pizatto (michelle.pizzato@poa.ifrs.edu.br) Instituto Federal do Rio Grande do Sul - Campus Porto Alegre, RS.

\begin{abstract}
Resumo:
O presente artigo pretende apresentar e discutir a experimentação contextualizada e interdisciplinar como uma proposta para o ensino de ciências. Para tal, inicialmente explicitam-se os conceitos de contextualização e interdisciplinaridade fundamentandoos teoricamente e discutindo-os na perspectiva que vislumbre possibilidades e contrapontos para a sua efetividade em sala de aula. Em seguida, apresenta-se a proposta de experimentação contextualizada e interdisciplinar evidenciada no livro "Dialogando Ciência entre sabores, odores e aromas contextualizando os alimentos química e biologicamente", que pretende uma experimentação voltada para um contexto real e de vivência do aluno, no caso os alimentos, buscando explorar de forma ampla e dialogada entre diferentes áreas do saber, principalmente a Química e a Biologia.
\end{abstract}

Palavras-chave: Experimentação; contextualização; interdisciplinaridade.

\begin{abstract}
:
This article intends to present and discuss contextualized and interdisciplinary experimentation as a proposal for the teaching of science. Initially, the concepts of contextualization and interdisciplinarity are theoretically explained, and then discussed in the perspective that predict possibilities and counterpoints for their effectiveness in the classroom. Next, we present the proposal of contextual and interdisciplinary experimentation evidenced in the book "Dialoguing Science among flavors, odors and aromas contextualizing the food chemically and biologically", which intends an experimentation focused on a real context and student's experiences, in the case of food, seeking to explore in a broad and dialogical way, different areas of knowledge, mainly Chemistry and Biology.
\end{abstract}


Palavras-chave traduzidas: Experimentation; contextualization; interdisciplinarity.

\section{INTRODUÇÃO}

A experimentação ainda é justificativa para pesquisas na área do ensino de ciências: as razões são diversas e comumente se centram na sua efetividade em sala de aula, na apropriação de conceitos científicos, nos objetivos da sua abordagem, na aquisição de habilidades para o laboratório e no seu caráter motivador (HODSON, 1994; GALIAZZI et al., 2001; LABURU; MAMPRIN; SALVADEGO, 2011).

A experimentação no ensino de ciências está relacionada à promoção de habilidades processuais tais como: "observar, classificar, questionar e levantar hipóteses, fundamentais para o desenvolvimento de habilidades mais avançadas, como planejar, prever e interpretar dados" (WARD et al., 2010, p.35). Contudo Espinoza (2010, p. 83) acredita que o experimento "constitui um artifício didático que não é proposto com o intuito de motivar, imitar ou mostrar como se produz conhecimento científico, mas que representa, [...] uma estratégia, para favorecer o aprendizado, [...] principalmente a cargo do aluno".

Entretanto, acreditamos que não basta propor um experimento, a forma de condução e as abordagens propiciadas durante a realização da atividade experimental: os questionamentos, as discussões e as reflexões fomentadas, é que determinarão se esta proposta será, ou não, eficaz no ensino. Outro aspecto a considerar, são as possibilidades oferecidas pelo experimento, no sentido de favorecer a aprendizagem.

Neste sentido, a contextualização é fundamental, pois oferece um espaço de participação para o aluno, instigando o compartilhamento das ideias advindas do conhecimento prévio sobre o fenômeno proposto. O contexto aqui é entendido como uma situação, o entorno em que o experimento é apresentado. Também defendemos que a experimentação quando surge através de um contexto que possibilita o diálogo com outros saberes, é explorada de forma ampla, transcendendo os conteúdos conceituais de uma área do conhecimento; por sua complexidade, permite novos olhares que se comunicam entre si ou não, em relação ao fenômeno estudado, propiciando assim a interdisciplinaridade.

No presente artigo, pretendemos apresentar aspectos essenciais que 
movimentaram a inclusão desses dois termos: contextualização e interdisciplinaridade, como eixos articuladores da experimentação no ensino de ciências, na qual acreditamos e propomos no livro: Dialogando Ciências entre sabores e odores: contextualizando os alimentos química e biologicamente (2010), de nossa autoria.

\section{A CONTEXTUALIZAÇÃO NO ENSINO DE CIÊNCIAS: A RELAÇÃO ENTRE SUJEITO E OBJETO}

A contextualização do ensino foi preconizada nas Diretrizes Curriculares Nacionais para o Ensino Médio - DCN (BRASIL, 1998) e atende a Lei de Diretrizes e Bases da Educação Nacional (BRASIL, 1996) que estabelece como uma das finalidades do Ensino Médio: a preparação básica para o trabalho e a cidadania do educando, para continuar aprendendo, de modo a ser capaz de se adaptar, com flexibilidade, às novas condições de ocupação ou aperfeiçoamento posteriores.

Elas abrigam uma visão do conhecimento e das formas de tratá-los para ensinar e para aprender que permite dar significado integrador a duas outras dimensões do currículo de forma a evitar transformá-las em novas dualidades ou reforçar as já existentes: base nacional comum/parte diversificada, e formação geral/preparação básica para o trabalho (BRASIL, 1998, p. 50).

O fato é que este termo está impregnado nos objetivos educacionais, sendo anunciado nos discursos de professores e referenciado por vários pesquisadores em educação em ciências. Os documentos oficiais apresentam que a contextualização do conteúdo em sala de aula, indica essencialmente assumir que todo conhecimento, envolve uma relação entre sujeito e objeto. Ainda enfatizam que a contextualização, é concebida como recurso por meio do qual se busca dar um novo significado ao conhecimento escolar, possibilitando ao aluno uma aprendizagem mais significativa (BRASIL, 1999).

Mesmo presente nos documentos curriculares oficiais mais recentes o significado de contextualização, possui origens em propostas anteriores para o ensino de um modo geral. Nas décadas de 1980 e 1990 a valorização do cotidiano do aluno no processo de aprendizagem escolar era proclamada no meio educacional. Fracalanza, Amaral e Gouveia (1986) apresentam duas versões que justificam a utilização do cotidiano nos processos de ensino e aprendizagem: uma delas se preocupava com aplicação do aprendizado na solução de problemas práticos da vida do aluno e outra anunciava o uso do cotidiano, como forma de motivação do aluno. Os autores ressaltam que essas 
versões possuem equívocos, relacionados ao risco de transformar o ensino de ciências em um curso de tecnologia caseira, e a noção difundida pelos livros didáticos de um cotidiano padronizado e estereotipado. Já naquela época acreditava-se que a contribuição do uso do cotidiano na aprendizagem precisava de reformulação, buscando “[...] a articulação entre cotidiano, que representa o conteúdo vivido pelo aluno, e os níveis mais conceituais e abstratos da aprendizagem" (FRACALANZA; AMARAL; GOUVEIA, 1986, p. 119).

Neste sentido, Canto e Peruzzo (1993) buscaram enfatizar o cotidiano como uma proposta de abordagem no ensino de química, no material didático: Química na abordagem do cotidiano. Esta iniciativa foi muito bem recebida por parte dos professores de química, sendo utilizado até os dias de hoje. Contudo Wartha, Silva e Bejarano (2013) apontam que pesquisadores têm considerado que a abordagem do cotidiano neste material é superficial, apresentando relações esparsas entre contextos e conhecimentos científicos.

A Proposta Curricular para o Ensino de Química: $2^{\circ}$ grau (1988) para o Estado São Paulo, tinha como um dos princípios orientadores: o cotidiano no ensino de Química. A concepção de cotidiano defendida pelos autores da proposta tinha como base a análise de situações reais, privilegiando os

[...] conteúdos contextualizados, isto é, que tenham significação humana e social, propõe-se que se tome como ponto de partida situações de interesse imediato do aluno, o que ele vive, conhece ou sofre influências e que se atinjam os conhecimentos químicos historicamente elaborados, de modo que lhe permitam analisar criticamente a aplicação destes na sociedade (SÃO PAULO, 1988, p. 17-18).

Em se tratando de propostas problematizadoras do cotidiano, destacamos Lutfi (1988; 1992) que em suas obras: "Cotidiano e Educação em Química: os aditivos em alimentos como propostos para o ensino de química no $2^{\circ}$ grau", e "Os ferrados e os cromados: produção social e apropriação privada do conhecimento químico" apresentam que os "processos vividos por todos e não refletidos, espontâneos, a reflexão sobre eles pode levar-nos a níveis acima da cotidianidade" (LUFTI, 1992, p. 16). Estas propostas contemplaram os conteúdos conceituais, numa relação de compreensão e possíveis implicações sociais, ambientais e políticas. Lutfi $(1988,1992)$ problematiza as questões cotidianas de uma forma que transcende a sala de aula: 
O cotidiano não como uma relação individual com a sociedade, pois existem mecanismos de acomodação e alienação que permeiam as classes sociais, mas considera a necessidade de fazer emergir o extraordinário daquilo que é ordinário, ou seja, buscar naquilo que nos pareça mais comum, mais próximo, o que existe de extraordinário, que foge ao bom senso, e que tem uma explicação que precisa ser desvelada (LUFTI, 1992, p. 15).

A utilização de fatos e conteúdos relacionados com o cotidiano foi sendo incorporada por vários projetos em educação química e possibilitaram um novo olhar na elaboração dos materiais didáticos. É sabido que a partir da promulgação dos Parâmetros Curriculares Nacionais para o Ensino Médio - PCNEM em 1999, o termo cotidiano foi substituído por contextualização, e que muitas vezes estes termos são utilizados como sinônimos, implicando certo reducionismo, assumindo entendimentos como: simples exemplificação do conhecimento científico nos fatos cotidianos (WARTHA; SILVA; BEJARANO, 2013). Kato e Kawasaki (2011, p. 39) ressaltam que, “[...] contextualizar o ensino é aproximar o conteúdo formal (científico) do conhecimento trazido pelo aluno (não formal), para que o conteúdo escolar torne-se interessante e significativo para ele".

A concepção do termo contextualização é consequência da apropriação de muitos discursos curriculares, nacionais e internacionais, em contextos diversos acadêmicos, oficiais e das agências multilaterais. A interpretação para o contexto nas diretrizes curriculares para o Ensino Médio confere três aspectos: trabalho; cidadania, vida pessoal, cotidiana e convivência. Aliado ao mundo do trabalho está a tecnologia, que por excelência é capaz de contextualizar os conhecimentos (LOPES, 2008).

O que fundamenta o conceito de contextualização são as ideias da aprendizagem situada de David Stein (1998), que conforme Lopes (2008) está baseada na vivência de situações do dia a dia, segundo os interesses dos alunos, na produção de significados, desvinculadas da pura transmissão de conceitos. Ainda salientamos que "[...] a ideia de contextualização também aparece ligada à valorização do cotidiano: é defendida a relação intrínseca entre os saberes escolares e as questões concretas da vida dos alunos" (LOPES, 2008, p. 143).

A aprendizagem situada (contextualizada) é associada à preocupação em retirar o aluno da condição de espectador passivo, em produzir uma aprendizagem significativa e em desenvolver o conhecimento espontâneo do abstrato. Com referências constantes a Vygostky e a Piaget, a 
contextualização nesses momentos aproxima-se mais da valorização dos saberes prévios dos alunos. Nesse caso, contextualizar é, sobretudo, não entender o aluno como tábula rasa (BRASIL, 1999, p. 1- 4).

Kato e Kawasaki (2011, p. 36) apresentam que a contextualização “[...] no ensino surgiu em um momento da educação formal no qual os conteúdos escolares eram apresentados de forma fragmentada e isolada, apartados de seus contextos de produção científica, educacional e social". Lopes (2002) explicita que o maior problema relacionado à questão da fragmentação dos conteúdos pela escola é a retirada dos conceitos de sua historicidade e sua problemática.

\begin{abstract}
Os saberes ensinados aparecem como saberes sem produtores, sem origem, sem lugar, transcendentes ao tempo, ensinando-se apenas o resultado, isolando-os da história de construção do conceito, retirando-os do conjunto de problemas e questões que os originaram. Nesta perspectiva de ensino, os currículos escolares tornam-se inadequados à realidade em que estão inseridos, pois estão centrados em conteúdos muito formais e distantes do mundo vivido pelos alunos, sem qualquer preocupação com os contextos que são mais próximos e significativos para os alunos e sem fazer a ponte entre o que se aprende na escola e o que se faz, vive e observa no dia a dia (KATO; KAWASAKI, 2011, p. 36).
\end{abstract}

Essas discussões reafirmam, a contextualização como necessária e imprescindível tendo em vista que,

O enraizamento na construção dos significados constitui-se por meio do aproveitamento e da incorporação de relações vivenciadas e valorizadas no contexto em que se originam na trama de relações em que a realidade é tecida, em outras palavras, trata-se de uma contextuação (WARTHA; SILVA; BEJARANO, 2013, p. 86).

Santos e Mortimer (1999 apud SILVA; MARCONDES 2010), estudando as concepções de um grupo de professores a respeito da contextualização no ensino de química, identificaram três diferentes entendimentos: a contextualização como estratégia para facilitar a aprendizagem; como descrição científica de fatos e processos do cotidiano do aluno e como desenvolvimento de atitudes e valores para a formação de um cidadão crítico. Os autores apontaram que grande parte dos professores pesquisados entende a contextualização como uma descrição científica de fatos e processos do cotidiano do aluno.

A contextualização apresentada nas Orientações Curriculares para o Ensino Médio (2006) pode ser entendida por meio de abordagem de temas sociais e situações de alta vivência, metodologias apresentadas por Santos e Schnetzler (1997) e Maldaner (2000). Contextualizar como bem explicitam Galiazzi e Gonçalves (2004, p. 246) “[...] implica, 
em síntese, trazer para a discussão em sala de aula aspectos culturais, econômicos, políticos e sociais relacionados com ele".

Zanon (2008) reitera que desenvolver vínculos entre os conteúdos escolares e aspectos da realidade vivencial dos alunos constitui-se um desafio e que não é simples. A autora evidencia que a problematização de uma situação real com o objetivo de interpretá-lo à luz das teorias científicas, buscando contextualizar os conceitos científicos a serem significados, é algo desafiador. Neste sentido, outra demanda é necessária: a ampliação dos horizontes do cotidiano, complexificando os conceitos científicos em interações que possam ser abordadas nas aulas de ciências.

\begin{abstract}
A aprendizagem situada, retirando o aluno da condição de espectador passivo, promove uma aprendizagem significativa, aliada ao desenvolvimento de conhecimentos abstratos: professor e alunos atuam como sujeitos ativos, em contextos interativos que favorecem a mediação de linguagens específicas, valorizadas, sobretudo, em sua dimensão constitutiva, para além da comunicativa (ZANON, 2008, p. 256).
\end{abstract}

Os conceitos e implicações da contextualização apresentados e discutidos até aqui, revelam que o cotidiano surge como ponto principal para se pensar o contexto, onde se busca a aplicação dos conhecimentos científicos, que na maioria das vezes precisa ser desvelado. A atuação do professor neste processo é imprescindível, ele é quem promove a articulação dos saberes advindos dos alunos e também os conhecimentos científicos manifestos no contexto escolhido.

É preciso superar a visão simplista e reducionista tanto do conceito de cotidiano e contextualização quanto das formas de abordagem e desenvolvimento de temas, projetos, sequências didáticas que pretendem trabalhar desta forma. Wartha, Silva e Bejarano (2013) discutem os avanços e contrapontos destas duas temáticas e evidenciam que o conceito de cotidiano apresentado por Lufti $(1988,1992)$ se fundamenta nas ideias de Agnes Heller e Henri Lefebvre.

Heller (1989 apud WARTHA; SILVA; BEJARANO, 2013) pontua que alguns esquemas de comportamentos e pensamentos apresentados na vida cotidiana necessitam de estudo, pois as ações concebidas pelas pessoas demonstram-se sem a reflexão consciente e crítica. Considerando que são ações relacionadas a experiências empíricas, exigindo menor esforço e consequentemente demandam pouca reflexão de sua ação. "Nessa forma de ver a vida cotidiana, os indivíduos agem e pensam por meio de 
generalizações tradicionalmente aceitas na sociedade e que ele mesmo estabelece a partir de suas vivências" (WARTHA; SILVA; BEJARANO, 2013, p.89).

Lefebvre (2000 apud WARTHA; SILVA; BEJARANO 2013) explicita sua tríade dos espaços sociais, onde acontece a vida cotidiana, sendo ela, o espaço vivido, o espaço percebido e o espaço concebido. Para este autor o espaço vivido é influenciado fortemente pelos outros dois espaços, descrito pelos momentos do dia a dia do indivíduo, marcado pela prática social. Ainda “[...] fundamenta essa visão argumentando que no espaço percebido ocorrem as significações materialistas, empíricas, impregnadas pela atmosfera sociopolítica, pois se trata de um espaço tomado pela mediação" (WARTHA; SILVA; BEJARANO, 2013, p.89).

A intenção de discutir o conceito de cotidiano e contextualização no ensino de ciências, em particular no viés da experimentação, consiste em acreditar nas possibilidades efetivas de promoção do ensino e da aprendizagem dos conceitos científicos por meio desta abordagem. Entendemos através de diversos autores que a contextualização é necessária e defendemos a abordagem do cotidiano a partir de Lutfi $(1988,1992)$. A problematização de questões envolvendo as vivências dos alunos requer estudo e interação com outras áreas do saber. E então, acreditamos na contextualização do ensino, como algo que transcende a sala de aula, que problematiza e interage com os saberes dos alunos e que promove a aprendizagem significativa. Nesta perspectiva se configura a experimentação que emerge de fazeres contextualizados, vivenciados e problematizados nas aulas.

Neste viés de discussões, admitimos que o contexto é amplo e complexo, necessitando de entendimentos que extrapolam os conteúdos específicos de uma disciplina, requer outros saberes e olhares. Então, é que adotamos a interdisciplinaridade como algo capaz de proporcionar e explorar as prerrogativas assinaladas por nós, no livro: Dialogando Ciências entre sabores, odores e aromas contextualizando os alimentos química e biologicamente (2010).

\section{INTERDISCIPLINARIDADE COMO FORMA DE CONTEXTUALIZAR O ENSINO}

A interdisciplinaridade como conceito e abordagem há muito é alvo de debates educacionais. Os discursos sobre interdisciplinaridade foram disseminados mais fortemente e essencialmente a partir das pesquisas de Hilton Japiassu (décadas de 1960 
e 1970) e dos trabalhos de Ivani Fazenda, a partir da década de 1980; ainda teóricos no campo do currículo como Jurjo Torres Santomé (1998). As críticas a fragmentação do conhecimento escolar não são recentes, mesmo que ainda não tenha sido incorporada por professores em seus fazeres escolares, fomentam discussões partindo das demandas socioeconômicas.

Abreu; Lopes (2010) pontuam aspectos relevantes a favor do conhecimento necessário para o modelo de desenvolvimento que ora se apresenta na sociedade,

\begin{abstract}
A flexibilização das barreiras nacionais e internacionais, o avanço tecnológico, o desenvolvimento dos processos de produção e a instabilidade do mercado, todos esses fatores contribuíram para um aumento das informações disponíveis a um maior número de pessoas, configurando novas relações sociais e produtivas, marcadas pela competição entre a capacidade de acessar bancos de dados distintos e explorar a interpretação dessas bases. Estabelecem-se, assim, novos parâmetros para o desenvolvimento pessoal e profissional (ABREU; LOPES, 2010, p. 78).
\end{abstract}

A partir, dessas premissas, é que se difundiu a ideia de que o conhecimento necessário para este modelo de desenvolvimento deve estar inter-relacionado. Faz-se necessário a demanda por determinadas competências como: criatividade, flexibilidade, trabalho em equipe, capacidade de resolver problemas; ampliando as críticas a fragmentação do conhecimento escolar e reforçando a ideia de um ensino mais integrado, com vistas à formação de um cidadão, capaz de adaptar-se e inserir-se no contexto social e produtivo. Assim, conceitos como integração e interdisciplinaridade tornaram-se visíveis no contexto social brasileiro e incorporados aos documentos oficiais curriculares, como eixo estruturador (ABREU; LOPES, 2010).

As Diretrizes Curriculares Nacionais Gerais para a Educação Básica (BRASIL, 2013), consideram que a escola frente às demandas da atualidade “[...] precisa ser reinventada". Candau (2012) apresenta aspectos importantes que impulsionam a reinvenção da escola: as formas de acesso ao conhecimento são muitas e não é exclusividade da escola e a revolução ocasionada pelo impacto dos meios de comunicação em massa, em especial a informática, mostrando outras formas de construção do conhecimento. Este movimento exige “[...] sujeitos inventivos, participativos, cooperativos, preparados para diversificadas inserções sociais, políticas, culturais, laborais e, ao mesmo tempo, capazes de intervir e problematizar as formas de produção e de vida" (BRASIL, 2010, p. 18). 
A reinvenção da escola prioriza novos enfoques: “[...] um espaço de diálogo entre diferentes saberes - científico, social, escolar, etc. e linguagens; a relação com a articulação entre igualdade e diferença; a questão da cidadania como prática social cotidiana" (CANDAU, 2012, p. 14-15). E então a organização e gestão do currículo devem ser repensadas, e neste sentido, é que se insere a interdisciplinaridade.

As Diretrizes Curriculares Nacionais Gerais para a Educação Básica (2013) apontam que,

\begin{abstract}
A interdisciplinaridade pressupõe a transferência de métodos de uma disciplina para outra. Ultrapassa-as, mas sua finalidade inscreve-se no estudo disciplinar. Pela abordagem interdisciplinar ocorre a transversalidade do conhecimento constitutivo de diferentes disciplinas, por meio da ação didático-pedagógica mediada pela pedagogia dos projetos temáticos. Estes facilitam a organização coletiva e cooperativa do trabalho pedagógico, embora sejam ainda recursos que vêm sendo utilizados de modo restrito e, às vezes, equivocados (BRASIL, 2013, p. 28).
\end{abstract}

Os entendimentos apresentados pelas Diretrizes Curriculares Nacionais Gerais para a Educação Básica (2013) consideram-na como abordagem teórico-metodológica, com ênfase no trabalho de integração das diferentes áreas do conhecimento, na efetiva cooperação e troca, aberta ao diálogo e ao planejamento.

Thiesen (2008) enquanto discute em seu artigo A interdisciplinaridade como um movimento articulador no processo ensino e aprendizagem, apresenta que a finalidade da interdisciplinaridade no processo de ensinar e de aprender na escolarização formal, visa articular as abordagens pedagógica e epistemológica, considerando seus avanços, limitações, conflitos e consensos.

Nesta perspectiva, a interdisciplinaridade será

[...] articuladora do processo de ensino e de aprendizagem na medida em que se produzir como atitude (Fazenda, 1979), como modo de pensar (Morin, 2005), como pressuposto na organização curricular (Japiassu, 1976), como fundamento para as opções metodológicas do ensinar (Gadotti, 2004), ou ainda como elemento orientador na formação dos profissionais da educação (THIESEN, 2008, p. 546).

O que percebemos, é que conceitualmente a interdisciplinaridade é um movimento que visa uma reação alternativa, frente à abordagem disciplinar normalizadora, tanto no ensino quanto na pesquisa, dos diversos objetos de estudo. Todavia independentemente da concepção de cada autor, a interdisciplinaridade está 
sempre associada a possibilidade de superação da fragmentação das ciências e dos conhecimentos produzidos e sistematizados por elas, exprimindo a resistência a um saber parcelado (THIESEN, 2008).

Zucolotto et al. (2004, p. 330) afirmam que “[...] interdisciplinaridade é um conceito a pressupor e necessitar de disciplinas para existir; que ele se configura como uma relação entre tais disciplinas, sem alterar seus campos iniciais de ação". Furlanetto (2014) destaca que uma abordagem interdisciplinar, busca construir sob medida uma perspectiva apropriada a singularidade da situação. E então, “[ [...] não rejeita os conhecimentos disciplinares especializados, pelo contrário, leva-os em conta e os articula para construir respostas específicas para cada situação" (FURLANETTO, 2014, p. 65). As Orientações Curriculares Nacionais para o Ensino Médio evidenciam a essencialidade de cada saber disciplinar "[...] legitimado no papel que a apropriação da linguagem e do pensamento próprio a cada cultura científica assume, no desenvolvimento das abordagens, das ações e das interlocuções” (BRASIL, 2006, p. 118).

Ressaltamos que a dimensão disciplinar do conhecimento não pode ser discutida, no sentido de anular ou superar, o que se propõe "[...] é uma profunda revisão de pensamento, que deve caminhar no sentido da intensificação do diálogo, das trocas, da integração conceitual e metodológica nos diferentes campos do saber" (THIESEN, 2008, p. 548).

Nesta intenção, é imprescindível selecionar saberes e conhecimentos significativos, conectados ao que o aluno já tenha apreendido e que tenha sentido, contribuindo para formar identidades pautadas por autonomia, solidariedade e participação na sociedade. Desta forma, precisam ser considerados os saberes dos alunos, o que gostariam de aprender e o que se considera que precisam aprender. $\mathrm{E}$ então, são imprescindíveis metodologias de ensino inovadoras, não conservadoras, que proporcionem a participação ativa, interessada e comprometida no processo de aprender, privilegiando não somente os conhecimentos, mas que abarque a contextualização, experimentação, vivências e convivência em tempos e espaços escolares e extraescolares, por meio de aulas e situações diversas, ainda nos campos da cultura, do esporte e do lazer (BRASIL, 2013).

A concepção de interdisciplinaridade apresentada nas Diretrizes Curriculares 
Nacionais Gerais para a Educação Básica (2013) está baseada nas ideias de metodologias mistas (SANTOMÉ, 1998), as quais são desenvolvidas em, pelo menos, dois espaços e tempos: destinado ao aprofundamento conceitual no interior das disciplinas e voltado às atividades integradoras.

Neste sentido, Santomé (1998) alerta para a permanente busca da interdisciplinaridade, tendo em vista que sua efetividade é complexa e que somente o exercício sistemático desse fazer proporcionará, o como fazer.

\begin{abstract}
A interdisciplinaridade é um objetivo nunca completamente alcançado e por isso deve ser permanentemente buscado. Não apenas uma proposta teórica, mas sobretudo uma prática. Sua perfectibilidade é realizada na prática, na medida em que são feitas experiências reais de trabalho em equipe, exercitam-se suas possibilidades, problemas e limitações. É uma condição necessária para a pesquisa e a criação de modelos mais explicativos desta realidade tão complexa e difícil de abranger (SANTOMÉ, 1998, p. 66).
\end{abstract}

Zucolotto et al. (2004) reiteram no artigo: Do nome das coisas à disciplina dos termos: $O$ que sabemos? que problemas da efetividade da interdisciplinaridade estão muito mais relacionados às dificuldades de integrar as pessoas, do que as disciplinas. $\mathrm{E}$ então afirmam que "[...] o impedimento de um projeto interdisciplinar não está especificamente nos conteúdos acadêmicos e nas suas possíveis inter-relações, mas no conhecimento dos docentes e em sua capacidade de entender e perceber as interrelações" (ZUCOLOTTO et al., 2004, p. 330).

Desta forma, é fundamental pensar a prática da interdisciplinaridade na formação inicial e continuada de professores, para que se possa efetivar em sala de aula. Como propor atividades interdisciplinares, se na formação desse professor, ele não foi desafiado a pensar de forma integrada, se recebeu somente parte de coisas, um ensino fragmentado e isolado do contexto em que foi produzido?

Thiesen (2008) apresenta como incipiente no contexto educacional, o desenvolvimento de experiências verdadeiramente interdisciplinares, e expressa que,

Não é difícil identificar as razões dessas limitações; basta que verifiquemos o modelo disciplinar e desconectado de formação presente nas universidades, lembrar da forma fragmentária como estão estruturados os currículos escolares, a lógica funcional e racionalista que o poder público e a iniciativa privada utilizam para organizar seus quadros de pessoal técnico e docente, a resistência dos educadores quando questionados sobre os limites, a importância e a relevância de sua disciplina e, finalmente, as exigências de 
alguns setores da sociedade que insistem num saber cada vez mais utilitário (THIESEN, 2008, p. 550).

Nesta perspectiva, Zucolotto et al. (2004, p. 331) sugerem “[...] ser mais fácil começar de novo, de maneira diferente, do que propor uma mudança dentro do que já existe". E continuam explicitando um novo olhar para interdisciplinaridade, as possibilidades de se pensar a integração dos saberes.

A interdisciplinaridade é favorecida pela contextualização, pois as implicações que envolvem os diversos contextos não são disciplinares por excelência. As Orientações Curriculares Nacionais para o Ensino Médio (2006) avançam para uma enculturação contextualizada e aliada a interdisciplinaridade.

\begin{abstract}
Assim, a enculturação contextualizada em Química, aliada à interdisciplinaridade não superficial, traz à tona limites dos saberes e conceitos cotidianos e, sem negá-los nem substituí-los, amplia-os nas abordagens transformadoras, possibilitadas pelos conhecimentos emergentes e pelas ações das condições potencializadoras da qualidade de vida socioambiental (BRASIL, 2006, p.118).
\end{abstract}

Após esta breve discussão, podemos considerar alguns aspectos pertinentes a interdisciplinaridade, na perspectiva da experimentação como articuladora do processo de ensino e de aprendizagem. Faz-se necessário perceber como explicita Thiesen (2008, p. 549),

[...] que a interdisciplinaridade não se efetiva se não transcendermos a visão
fragmentada e o plano fenomênico, ambos marcados pelo paradigma
empirista e positivista. A escola precisa de um movimento que proclame a
inteligência interdisciplinar, integrar no lugar de dicotomizar, religar no lugar
de desconectar, problematizar no lugar de dogmatizar e questionar aquilo que
se impõe como verdade absoluta.

E neste viés de implicações, a escola, lugar por excelência da aprendizagem, produção e reconstrução de conhecimento, precisa se revestir e assumir as transformações da ciência contemporânea, legitimar as exigências interdisciplinares que permeiam a construção de novos conhecimentos. Urge que a escola acompanhe o ritmo das mudanças que se operam em todos os segmentos que compõem a sociedade; o mundo está interconectado, interdisciplinarizado e complexo (THIESEN, 2008).

Acreditamos numa concepção de interdisciplinaridade em que o professor assuma a postura de quem é capaz de partilhar o domínio do saber, e para tal é necessário ter coragem, sair da zona de conforto, abandonar a visão de exclusividade do domínio e do 
poder que os conhecimentos disciplinares oferecem e aventurar-se num campo que é de todos e ao mesmo tempo não é de ninguém.

Defendemos a interdisciplinaridade, como um movimento importante na articulação entre o ensinar e o aprender e na perspectiva de Furlanetto (2014, p.73) que se vislumbra aqui, a interdisciplinaridade que "[...] emerge como uma possibilidade de conhecer que requer aberturas, encontros e diálogos possíveis a partir de uma lógica que une e relaciona".

\section{A PROPOSTA DE EXPERIMENTAÇÃO, CONTEXTUALIZADA E INTERDISCIPLINAR NO CONTEXTO DA ESCOLA.}

Acreditamos no que é explicitado por Fazenda (2011, p.17) que em um “[...] projeto interdisciplinar não se ensina, nem se aprende: vive-se, exerce-se". E que a responsabilidade individual e o envolvimento são marcas do projeto interdisciplinar, envolvimento no projeto em si, nas pessoas e nas instituições a ele pertencentes (FAZENDA, 2011).

É a partir dessa premissa que pensamos e estruturamos o livro Dialogando Ciência entre sabores, odores e aromas: contextualizando os alimentos química e biologicamente (2010), no caminhar de duas professoras que propuseram e materializou-se nesta obra que pretende uma experimentação voltada para um contexto real e de vivência do aluno, no caso os alimentos, buscando explorar de forma ampla e dialogada entre diferentes áreas do saber, principalmente a química e a biologia.

Dessa forma, pretendemos um novo olhar sobre as atividades experimentais, proporcionando, como bem explicitam Silva et al. (2010, p. 245) “[...] uma visão mais ampla dos fenômenos, revelando a complexidade da vida moderna e possibilitando a diversidade de abordagens. Esses novos contextos podem também promover uma mudança do papel da escola para sociedade". Esta proposta apresenta duas características importantes, mencionadas por Galiazzi e Gonçalves (2004) e amparadas pelas DCNs (2010), a contextualização e o diálogo entre as áreas do saber.

A proposta experimental do referido livro está estruturada em doze capítulos, que proporcionam o diálogo e a reflexão das áreas contempladas, desde o primeiro capítulo intitulado: "A química e a biologia na mesa das pessoas" enfatiza a alfabetização científica como abordagem na tomada de decisão. Em seguida: "Degustando a química e a biologia no ensino médio", a intenção é discutir como essas áreas de conhecimento 
são importantes e necessitam novas metodologias de abordagens. Também explicita a essencialidade de considerar, o aluno como possuidor de conhecimentos e fundamental no processo de ensino e de aprendizagem.

Estes dois primeiros capítulos possibilitam aos leitores a percepção de que os fenômenos a nossa volta precisam ser vivenciados na escola, como algo que necessita de problematização e que superar a fragmentação do ensino e da vida, faz emergir os significados e entendimentos, tornando-os mais atuantes e compromissados com o uso da ciência; para tal é imprescindível a contextualização dos conceitos e o diálogo entre as áreas do conhecimento.

O laboratório tem lugar especial nesta proposta: "A cozinha, (e) um verdadeiro laboratório", destacam-se os materiais necessários para se pensar um lugar para as experimentações que poderá ser até em uma cozinha, onde se preparam os alimentos. Houve o cuidado de sugerir materiais alternativos caso a escola não tenha laboratório e os devidos equipamentos, bem como os cuidados a serem tomados.

No capítulo seguinte: “Comer! Um fazer do vivo" abordou-se a organização sistêmica do ser vivo e neste cenário vislumbra-se a biologia com sua estrutura de conceitos e funcionalidade. Seguindo: "Alimentos: uma questão química, biológica, social, cultural e de cozinha", é apresentado um texto sucinto, que discute a importância das escolhas, perpassando pelo estudo e reflexão do que faz parte dos alimentos, e então conclui-se que alimentar-se é uma questão de cidadania.

No capítulo "Alimentação e sociedade - uma pitada de história", há um convite para uma viagem por alguns episódios históricos relacionados a hábitos culturais, buscando a reflexão dos fazeres e das escolhas com vistas a uma alimentação saudável. "Alimentos no sabor legal: legislação vigente", apresenta a mudança na relação do ser humano com os alimentos a partir da industrialização e as possibilidades de contaminação, consequentemente a criação da ANVISA (Agência Nacional de Vigilância Sanitária), em 1999.

É possível perceber que os temas abordados no referido livro movimentam discussões que transcendem os conceitos científicos disciplinares para uma discussão mais ampla que viabilize a integração entre as áreas do conhecimento (química e biologia, entre outras), no sentido de possibilitar ao professor e aos alunos abordagens 
que proclamem a "inteligência interdisciplinar", defendida por Thiesen, (2008), trazendo à tona temas como: alimentação e as questões socioculturais, que perpassam a história, os fazeres cotidianos, a importância da industrialização e a defesa pelo caseiro, problematizando a contaminação nos alimentos e permitindo olhares diversos para temas corriqueiros.

A partir do capítulo 8 até o 12, os experimentos são apresentados como atividades práticas $^{1}$, conforme o quadro 1 .

Quadro 1: Apresentação dos temas abordados, os conceitos e quantidade de atividades práticas dos capítulos. Fonte: Luca; Santos (2010).

\begin{tabular}{|c|c|c|}
\hline Capítulo & Abordagem Conceitual & Atividades Práticas \\
\hline 8. Ingredientes & Propriedades dos materiais & 10 \\
\hline 9. Preparando alimentos & Sistema material & 18 \\
\hline 10. Composição química e ação & Estudo das biomoléculas & \\
\hline biológica dos alimentos & & \\
\hline 11. Selecionando alimentos & Processos biológicos e & 5 \\
\hline
\end{tabular}

A experimentação proposta tem como trajeto obrigatório a exploração de conceitos que possam ter uma abordagem da química e da biologia, que tanto pode ser aplicada pelas duas áreas quanto por uma só, mas a fronteira epistemológica exige o diálogo entre essas áreas. A interdisciplinaridade é impulsionada por meio do Box intitulado: Aprofunde seus conhecimentos..., que tem a finalidade de fomentar leituras e discussões por meio de pequenos trechos de livros de divulgação científica e/ou paradidáticos. Essas leituras proporcionam discussões sobre os conceitos científicos desenvolvidos nos experimentos e também temas sociais que envolvem o estudo dos alimentos. Como os temas são abertos, a investigação e o estudo dos professores e

1 Como a definição do termo a ser adotado expressa a crença do proponente, ou seja, do professor no recurso pedagógico a ser utilizado, é imprescindível que este elabore a epistemologia do conceito. Sendo assim, considerar-se-á neste trabalho a concepção de Bonito (1996), que inclui experimentações no termo Atividades Práticas - Aps, adotado neste trabalho. 
alunos, oferecem possibilidades de pesquisa fora e dentro da sala de aula. Ainda, propomos atividades práticas que incentivam o aluno e o professor a organizar um workshop, visita ao supermercado, análise de rótulos, realização de uma receita de pão de queijo, debates envolvendo temas conflitantes da alimentação, entre outras; promovendo assim, a atitude ativa, o protagonismo dos alunos. Na figura 1, apresentamos um experimento e o Box: Aprofunde seus conhecimentos..., de forma a exemplificar como os experimentos apresentam-se no livro.

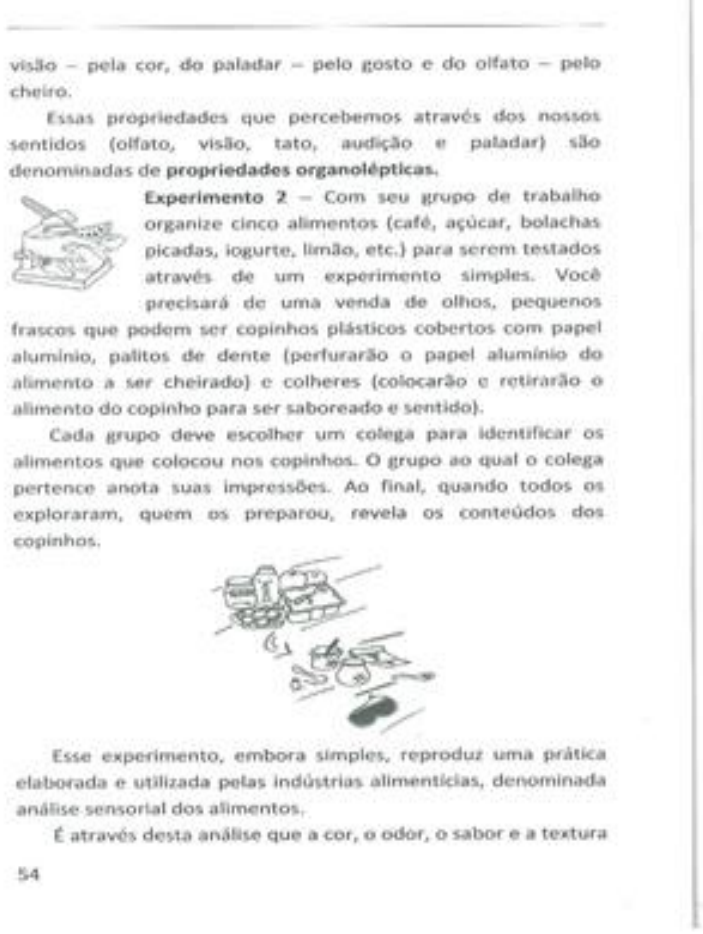

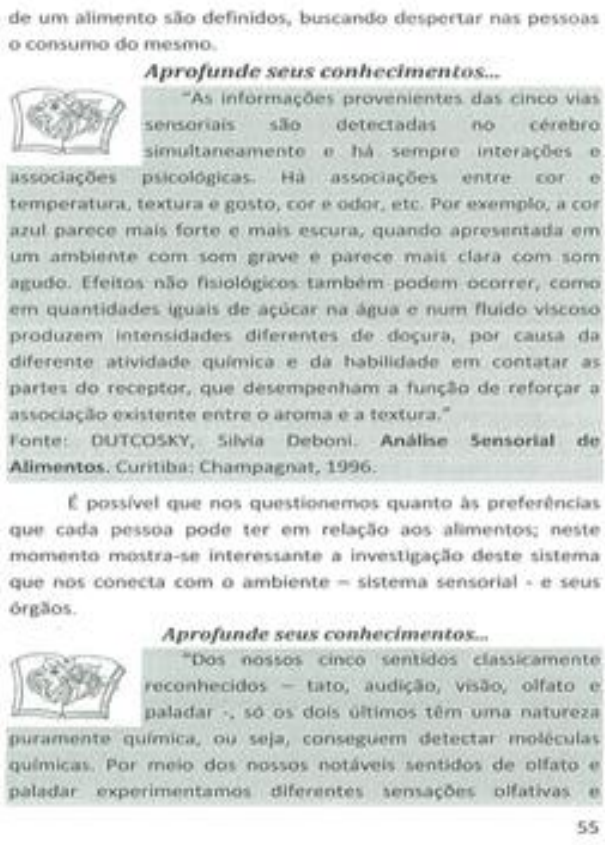

Figura 1: Experimento 2 - capítulo 8; e o Box: Aprofunde seus conhecimentos...

Salienta-se que a proposta dos experimentos não é rígida em sua execução, oferecendo ao professor a possibilidade de realizar os experimentos em diferentes sequências ou conforme o seu planejamento. Os materiais necessários para a execução dos experimentos são de fácil aquisição e não confere perigo de manipulação. Fica a critério do professor utilizá-los como demonstração, investigação ou resolução de problemas.

\section{UM OLHAR PARA A EXPERIMENTAÇÃO CONTEXTUALIZADA E INTERDISCIPLINAR: APROXIMAÇÕES E DISTANCIAMENTOS}

A partir dos pressupostos teóricos que foram nos constituindo (HODSON, 1994; GIORDAN, 1999; GALIAZZI et al., 2001; SILVA; MACHADO; TUNES, 2010; 
LABURÚ, MAMPRIN; SALVADEGO, 2011; LOPES, 2008; WARTHA; SILVA; BEJARANO, 2013; THIESEN, 2008; BRASIL, 2006, 2010; SANTOMÉ, 1998; KATO; KAWASAKI, 2011; LUTFI, 1988, 1992; ABREU; LOPES, 2010; ZUCOLOTTO et al., 2004; FURLANETTO, 2014), acreditamos numa experimentação que oportunize a indissociabilidade da teoria e prática, valorizando as concepções prévias dos alunos e confrontando-as com os discursos da ciência.

A viabilização do diálogo, através dos questionamentos propostos pelo professor em seu planejamento, é importante e favorece a investigação. Algo imprescindível na experimentação é a construção de argumentos que respondam aos questionamentos propostos por meio da leitura e da discussão em grupo, como forma de validação das teorias pessoais, colaborando para a autonomia e a socialização do conhecimento.

A contextualização e a interdisciplinaridade são importantes para os entendimentos dos diversos fenômenos nos quais estão inseridos os alunos, como cidadãos. A contextualização efetivada pela discussão de diversos contextos de vivência permite que tanto os professores de química como os de biologia, dialoguem com o mesmo objeto de estudo, buscando entendimentos em outras áreas do conhecimento. A interdisciplinaridade como possibilidade de integração dos conhecimentos nos contextos escolares, proporcionada pelo diálogo, é entendida como uma epistemologia de fronteira (FURLANETTO, 2014).

O planejamento é entendido como aspecto central da experimentação para que se possa pensar no professor como mediador, promovendo discussões além dos conteúdos conceituais, permitindo a problematização de situações reais, providas de significados. O professor deve evitar a realização do experimento pelo experimento, distante das implicações sociais, não contribuindo para os entendimentos de mundo e, consequentemente, não favorecendo o processo de apropriação dos conceitos científicos presentes.

A experimentação no ensino deve ser abordada e problematizada nos cursos de formação inicial e continuada de professores para que se possa discutir e fundamentarse teoricamente, superando a visão simplista, de que por meio da experimentação chegase às teorias estabelecidas nas Ciências, comprovando-as.

\section{REFERÊNCIAS}


ABREU, R. G. de; LOPES, A. C. A interdisciplinaridade e o Ensino de Química: uma leitura a partir das políticas de currículo. In: SANTOS, W. L. P. dos; MALDANER, O. A. Ensino de química em foco. Ijuí: Ed Unijui, 2010.

BONITO, J. Na procura da definição do conceito de "Actividades Práticas". Enseñanza de las Ciencias de la Tierra: Extra, 1996.

BRASIL. Diretrizes Curriculares Nacionais Gerais da Educação Básica. Ministério da Educação. Diretoria de Currículos e Educação Integral. Brasília: MEC, SEB, DICEI, 2013.

Orientações Curriculares para o Ensino Médio. Brasília: Ministério da Educação, Secretaria de Educação Básica, 2006.

Parâmetros Curriculares Nacionais do Ensino Médio. Brasília: MEC; SEMTEC, 1999.

Parâmetros Curriculares Nacionais: Ensino Médio. Brasília: Ministério da Educação, Secretaria de Educação Média e Tecnológica, 2002.

. Lei $\mathrm{n}^{\circ}$ 9.394/96 - 24 de dez. 1996. Estabelece as diretrizes e bases da educação nacional. Brasília, 1998.

CANDAU, V. M. (Org.) Reinventar a escola. 8.ed. Petrópolis, RJ: Vozes, 2001.

CANTO, E. L.; PERUZZO, F. M. Química na abordagem do cotidiano. São Paulo: Editora Moderna, 1993.

ESPINOZA, A.M.; Ciências na escola: novas perspectivas para a formação dos alunos. São Paulo: Ática, 2010.

FRACALANZA, H.; AMARAL, I. A. do; GOUVEIA, M. S. F. O ensino de Ciências no primeiro grau. São Paulo: Atual, 1986.

FURLANETTO, E. C. Interdisciplinaridade: uma epistemologia de fronteiras. In: ROSITO-BERKENBROCK, M. M. (Org). Interdisciplinaridade e transdisciplinaridade: políticas e práticas de formação de professores. Rio de Janeiro: Wak Editora, 2014. 
GALIAZZI , M.C. et al. Objetivos das atividades experimentais no Ensino de Médio: a pesquisa coletiva como modo de formação de professores de Ciências. Ciência e Educação, v.7, n.2, p. 249-263, 2001.

GONÇALVES, F. P. e GALIAZZI , M.C. A natureza das atividades experimentais no ensino de ciências: um programa de pesquisa educativa nos cursos de Licenciatura. In: MORAES, R.; MANCUSO, R. (Orgs.) Educação em ciências: produção de currículos e formação de professores. Ijuí: UNIJUÍ, p. 237-252, 2004.

HODSON, D. Hacia un enfoque más crítico del trabajo de laboratorio. Enseñanza de Las Ciencias, v.12, n.3, p.299-313, 1994.

KATO, D. S.; KAWASAKI, C. S. As concepções de contextualização do ensino em documentos curriculares oficiais e de professores de ciências. Ciência \& Educação, v. 17 , n. 1 , p. 35-50, 2011.

LABURÚ, C.E.; MAMPRIN, M. I. de L. L.; SALVADEGO, W. N. C. Professor das ciências naturais e a prática de atividades experimentais no ensino médio: uma análise segundo Charlot. Londrina: Eduel, 2011.

LOPES, A. C. Políticas de Integração Curricular. Rio de Janeiro: EDUERJ, 2008.

LUCA, A. G. de; SANTOS, S. A. dos. Dialogando Ciências entre sabores, odores e aromas: contextualizando os alimentos química e biologicamente. São Paulo: Editora Livraria da Física, 2010.

LUFTI, M. Cotidiano e Educação em química: os aditivos em alimentos como proposta para o ensino de química no $2^{\circ}$ grau. Ijuí: Unijuí, 1988.

Ferrados e cromados: produção social e apropriação privada do conhecimento químico. Ijuí: Unijuí, 1992.

SANTOMÉ, J. T. Globalização e interdisciplinaridade: o currículo integrado. Porto Alegre: Editora Artes Médicas Sul Ltda., 1998.

SÃO PAUlO (Estado). Proposta Curricular para o ensino de Química: $2^{\circ}$ grau.Secretaria da Educação. Coordenadoria de Estudos e Normas Pedagógicas. 2.ed. São Paulo: SE/CENP. 1988. 
SILVA, E. L. da; MARCONDES, M. E. R. Visões de contextualização de professores de química na elaboração de seus próprios materiais didáticos. Rev. Ensaio, v.12, n.01, p.101-118, jan./abr., 2010.

SILVA, R. T. et al. Contextualização e experimentação uma análise dos artigos publicados na seção “Experimentação no ensino de Química “da Revista Química Nova 2000 - 2008. Ensaio - Pesq. Educ. Ciênc., v.11, n.2, 2009.

THIESEN, J. da S. A interdisciplinaridade como um movimento articulador no processo ensino-aprendizagem. Revista Brasileira de Educação, v. 13 n. 39, p.545-598.set./dez. 2008.

WARTHA, E. J.; SILVA, E. L. da; BEJARANO, N. R. R. Cotidiano e Contextualização no Ensino de Química. Química Nova na Escola, n. 2, p. 84-91, 2013.

ZANON, L. B. Tendências Curriculares no Ensino de Ciências/Química: um olhar para a contextualização e a interdisciplinaridade como princípios de formação escolar. In: ROSA, M. I. P.; ROSSI, A. V. Educação química no Brasil: memórias, políticas e tendências. Campinas, SP: Editora Átomo, 2008.

ZUCOlOTTO, A. M. et al. Do nome das coisas á disciplina dos termos: O que sabemos? Integração, a.10, n. 39, p. 321 - 332, 2004. 